\title{
Exergy Analysis of a Solar Absorption Refrigeration System in Ngaoundere
}

\author{
Maurice Tenkeng1,2, Paiguy Armand Ngouateu Wouagfack ${ }^{2,3 *}$, Daniel Lissouck ${ }^{3}$, Réné Tchinda1,2 \\ ${ }^{1}$ L2MSP, Department of physics, University of Dschang, Dschang, Cameroon \\ ${ }^{2}$ LISIE, University Institute of Technology Fotso Victor, University of Dschang, Dschang, Cameroon \\ ${ }^{3}$ Department of Renewable Energy, Higher Technical Teachers' Training College, University of Buea, Kumba, Cameroon \\ Email: *ngouateupaiguy@yahoo.fr
}

How to cite this paper: Tenkeng, M., Wouagfack, P.A.N., Lissouck, D. and Tchinda, R. (2017) Exergy Analysis of a Solar Absorption Refrigeration System in Ngaoundere. Journal of Power and Energy Engineering, 5, 1-18.

https://doi.org/10.4236/jpee.2017.510001

Received: August 24, 2017

Accepted: October 22, 2017

Published: October 25, 2017

Copyright $\odot 2017$ by authors and Scientific Research Publishing Inc. This work is licensed under the Creative Commons Attribution International License (CC BY 4.0).

http://creativecommons.org/licenses/by/4.0/

\begin{abstract}
In this study, the first and second laws of thermodynamics are used to analyze the performance of a single-stage absorption refrigeration system powered by solar energy. The working pair used in this study is $\mathrm{LiBr}-\mathrm{H}_{2} \mathrm{O}$ where water $\left(\mathrm{H}_{2} \mathrm{O}\right)$ is the refrigerant and the lithium bromide $(\mathrm{LiBr})$ is the absorbent. A mathematical model based on exergy analysis is applied to analyse the system performance. Temperature, enthalpy, entropy, mass flow rate and exergy loss of each component including evacuated tube solar collector are evaluated. Furthermore, the overall coefficient of performance $\left(C O P_{\text {cooling }}\right)$ and the overall exergetic coefficient of performance $\left(E C O P_{\text {cooling }}\right)$ of the solar absorption system (absorption system coupled to an evacuated tube solar collector) for cooling purpose are calculated from the thermodynamic properties of the working fluids under weather conditions of Ngaoundere city, Cameroon. The calculations were done on the basis of a half hourly analysis from 6:30 AM to 6:30 $\mathrm{PM}$. The results were compared and they show that the exergy destruction highly occurs in the generator and the solar collector. The simulation results can be used for the thermodynamics optimization of solar absorption refrigeration systems.
\end{abstract}

\section{Keywords}

Refrigeration, Absorption, Exergy Analysis, Solar Collector

\section{Introduction}

The need of refresh air or refrigeration is becoming more and more important in the daily activities nowadays. The refrigerators are useful for making ice and for storing vaccines and food in areas where electricity is unavailable or high in cost. 
That is the case in Africa in general and Cameroon in particular. Passive cooling systems, that is: good insulation, double glazing or use of thermal mass and ventilation are no longer sufficient. Refrigeration which is one of the active cooling methods is studied here to enable numerous villages from remote areas to benefit from welfare offered by nature; areas where electricity is in short supply are also concerned. In Africa, people have the opportunity to contribute to the protection of the environment by fighting against global warming. This can be done through the use of renewable energy sources such as solar, wind, geothermal, wasted heat and so on. Most of African countries are exposed to the sun all over the year, even during rainy seasons. Solar energy can therefore be a great opportunity for people living in this continent. Among the solar refrigeration technologies, the solar thermal with single-effect absorption system with the mature technology come into view to be the best option [1].

In order to improve the performance of a solar absorption refrigeration system, many optimization studies based on the energy analysis have been done. Energy analysis takes into account the first law of thermodynamics which deals with the conversion of energy. This cannot show where the irreversibility occurs in a system that has many sources of energy [2]. The exergy analysis based on the second law of thermodynamics, is the only way to detect irreversibility in different components of the system [3].

In Ravikumar et al. [4] study, exergy analysis of a double-effect solar assisted absorption system is carried out and influence of generator I, generator II temperatures on exergy values is shown. In A. A. Hasan et al. [5] paper, a second law efficiency is defined relative to a reversible cycle and maximized in order to find the optimum operating conditions of the cycle. The cycle performance is investigated over a heat source temperature range of $330 \mathrm{~K}-470 \mathrm{~K}$. Ghaddar et al. [6] have carried out research into solar absorption system performance in Beirut. Ezzine et al. [7] conducted a study on solar systems assisted with the double effect absorption refrigeration. The irreversibility of each component in the chiller was quantified and the potential of each component to contribute to the overall system's energy efficiency was determined. A. Fellah et al. [8] studied the performance of a Driven Solar Absorption Refrigeration System and submitted the cycle, under different operating and design conditions, to analyze the optimum conditions for which the maximum refrigeration effect can be achieved. M. Talbi and B. Agnew [9] performed the exergy analysis of an absorption refrigerator using lithium bromide and water as the working fluids. Recently C. Onan et al. [10] carried out studies on the hourly exergy destruction for each component in solar assisted absorption cooling system. Heng-Yi Li et al. [11] evaluated exergy losses in each component of a New Small Concentrating Solar Power Plant in China and they have seen that the system could run at full capacity all day long. Jieting Wei et al. [12] experimented in 2013 operating characteristics of a Solar-Assisted Heating System in Changchun and they concluded that it was feasible and also have a certain effect. G.C. Tubreoumya, et al. [13] developed a mathematical model representing the evolution of heat and mass transfer at each com- 
ponent of a solar adsorption refrigerator in Burkina Faso. Their work focused on the aim at the Solar Assisted Absorption Refrigeration Systems (SAARS) and various environment conditions, exergy loss of each component was calculated separately. Also calculations have been done twice with the dead state temperature equal to $25^{\circ} \mathrm{C}$ as environmental temperature with a more realistic approach.

In order to analyse the system with a great accuracy, we decided to look more closely by the simulation of a half hour analysis, from 6:30 AM to 6:30 PM of a single stage absorption refrigeration system, using water-lithium bromide solution as working fluid with an Evacuated tube solar collector type. On the $15^{\text {th }}$ of January 2014, we went to Ngaoundere, Cameroon, to collect data, which are solar insolation and environmental temperature. The main focus of this study is concentrated on the exergy analysis of each component of the system, precisely the exergy loss [14]. The coefficient of performance (COP) and the exergetic coefficient of performance $(E C O P)$ of the system are also investigated.

\section{Description of the Model}

\subsection{Solar Absorption Refrigeration System Modeling}

The model of absorption system studied here is a single-effect or single-stage absorption refrigeration machine as shown in Figure 1. The system includes heat exchangers, a pump, valves and piping. Absorption systems are basically used to avoid the compression work. The working pair used here is $\mathrm{LiBr}-\mathrm{H}_{2} \mathrm{O}$, where $\mathrm{LiBr}$ is the absorbent and $\mathrm{H}_{2} \mathrm{O}$ is the refrigerant. This working pair offers good thermodynamic performance and is environmentally benign [15]. $\mathrm{LiBr}-\mathrm{H}_{2} \mathrm{O}$ absorption systems are the more suitable for solar application [16]. The environmental temperature is $25^{\circ} \mathrm{C}$. For the night, there is an auxiliary heater. The type of collector used is an evacuated one with selective surface and a total area of $10 \mathrm{~m}^{2}$. The work of the pump is neglected; there is no spill over at the evaporator. Solar insolation values and ambient temperatures for Ngaoundere city, Cameroonare are shown in Table 1. These values are taken from Ngaoundere Meteorological Service. Ambient temperature during cool season is maximum at $33.62^{\circ} \mathrm{C}$, and minimum at $25.41^{\circ} \mathrm{C}$. The angle of incidence of the collector is taken as $60^{\circ} \mathrm{C}$. Cool water, Chilled water and hot water flow rates are taken as $0.00474,0.00474$ and $0.05691 \mathrm{~kg} / \mathrm{s}$ respectively in the absorber, the condenser and the evaporator.

When the refrigerant vapour is coming from the evaporator, it's absorbed in a liquid strong solution. This liquid weak solution is pumped to higher pressure, where the refrigerant is boiled out of the solution by the additional heat, which is collected in solar system collectors and/or an auxiliary heating boiler. The refrigerant vapour is condensed by rejecting heat in the condenser and the pressure of saturated liquid refrigerant is reduced through an expansion valve. Heat transfer from the cooling space causes vaporization of the refrigerant at low pressure, and then flows to the absorber. The liquid strong solution returns to the absorber through a throttling valve whose purpose is to provide a pressure drop to 


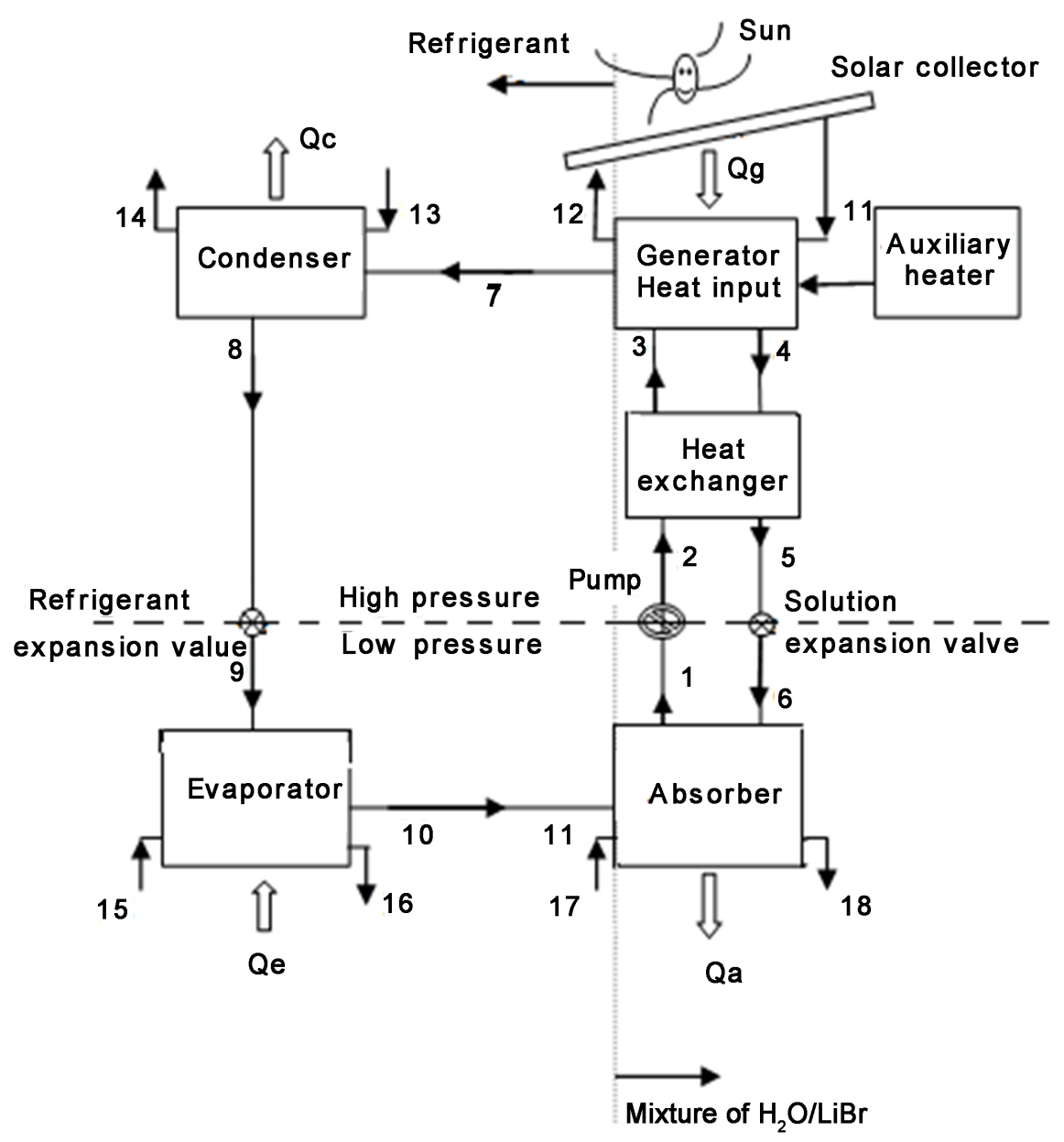

Figure 1. Single effect solar absorption refrigeration system.

maintain the difference between the generator and absorber. Heat recovery between the weak and strong solution is achieved through a solution heat exchanger and a constant flow rate of weak solution is maintained by a pump with negligible energy consumption [17].

Absorption is the process of attracting and holding moisture by substances called desiccants. Desiccants are sorbent materials that have an ability to attract and hold other gases or liquids and have a particular affinity for the refrigerant. During absorption the desiccant undergoes a chemical change as it takes in the moisture [18].

The basic idea of an absorption system is to avoid the compression work; this is done by using a suitable working pair [19]. The absorption process consist of transfer of material from one phase to another, interpenetrates the second phase to form solution [20].

\subsection{Refrigerant}

One of the most important elements of any refrigeration system is the refrigerant, since the working pair conditions and compatibility with the environment 
Table 1. Solar insolation and ambient temperature for Ngaoundere, on the $15^{\text {th }}$ of January 2014 .

\begin{tabular}{|c|c|c|}
\hline Time & Solar insolation $\left(\mathrm{kJ} \cdot \mathrm{m}^{-2}\right)$ & Temperature $\left({ }^{\circ} \mathrm{C}\right)$ \\
\hline $6: 30$ & 29.126 & 25.413 \\
\hline $7: 00$ & 153.846 & 26.875 \\
\hline $7: 30$ & 218.446 & 28.184 \\
\hline $8: 00$ & 326.923 & 28.375 \\
\hline $8: 30$ & 422.330 & 29.737 \\
\hline 9:00 & 528.846 & 29.875 \\
\hline $9: 30$ & 635.922 & 31.097 \\
\hline $10: 00$ & 750.000 & 31.300 \\
\hline $10: 30$ & 815.534 & 31.750 \\
\hline $11: 00$ & 865.385 & 32.313 \\
\hline $11: 30$ & 907.766 & 32.687 \\
\hline $12: 00$ & 932.692 & 33.062 \\
\hline $12: 30$ & 946.602 & 33.250 \\
\hline 13:00 & 951.923 & 33.437 \\
\hline $13: 30$ & 936.693 & 33.625 \\
\hline 14:00 & 875.000 & 33.437 \\
\hline $14: 30$ & 830.097 & 33.250 \\
\hline $15: 00$ & 721.154 & 32.875 \\
\hline $15: 30$ & 616.504 & 32.687 \\
\hline $16: 00$ & 509.615 & 32.500 \\
\hline $16: 30$ & 393.204 & 32.312 \\
\hline $17: 00$ & 298.077 & 32.125 \\
\hline $17: 30$ & 174.175 & 31.750 \\
\hline $18: 00$ & 134.615 & 31.562 \\
\hline $18: 30$ & 53.398 & 31.000 \\
\hline
\end{tabular}

principally depend on it. A refrigerant needs two requirements: high latent heat per unit volume and good thermal stability. The thermodynamic properties for $\mathrm{LiBr} / \mathrm{H}_{2} \mathrm{O}$ are pressure, temperature, concentration, enthalpy, entropy and density. These properties are interdependent and are necessary for computer simulation of absorption refrigeration systems. They are given by [9] and [21] [22] [23] [24].

\section{Thermodynamic Analysis}

The exergy of fluid stream can be defined by Arzu Şencan et al. [25]:

$$
\varphi=\left(h-h_{0}\right)-T_{0}\left(s-s_{0}\right)
$$


where $\varphi$ is the exergy of the fluid at temperature $T, h$ and $s$ are respectively enthalpy and entropy of the fluid, $h_{0}$ and $s_{0}$ are respectively the enthalpy and entropy of the fluid at environmental temperature $T_{0}(298.15 \mathrm{~K})$.

The specific exergy content of a mixture with $\mathrm{m}$ components is defined by $A$. Sözen et al. [26] as:

$$
\varphi=\sum_{n=1}^{m} x_{n} h_{n}-T_{0} \sum_{n=1}^{m} x_{n} s_{n}-\sum_{n=1}^{m} x_{n} \mu_{n 0}
$$

where $T_{0}$ is the reference temperature $\left(25^{\circ} \mathrm{C}\right), x_{n}$ is mass fraction and $\mu_{n 0}$ the chemical potential of the $n^{\text {th }}$ component of the mixture at $T_{0}$ and $P_{0}$.

The exergy loss or the availability loss in each component is given by Arzu Şencan et al:

$$
\Delta \varphi=\sum m_{i} \varphi_{i}-\sum m_{0} \varphi_{0}-\left[\sum Q\left(1-\frac{T_{0}}{T}\right)_{I}-\sum Q\left(1-\frac{T_{0}}{T}\right)_{\text {ref }}\right]+\sum W
$$

where $\Delta \varphi$ is the lost exergy or irreversibility that occurs in the process. The first two terms of the right hand side are the exergy of the inlet and outlet streams of the control volume. The third and fourth terms are the exergy associated with the heat transferred from the source maintained at a temperature $T$. The last term is the exergy of mechanical work added to the control volume. The term is negligible for absorption systems as the solution pump has very low power requirements.

The total exergy loss of absorption system is the sum of exergy loss in each component and is written as:

$$
\Delta \varphi=\sum_{n=1}^{m} \Delta \varphi_{n}
$$

De Vos (1992) [27] established equations for calculating the exergy loss to the collector per unit area as function of the exergy emitted from the sun minus the albedo of the earth and the radiation emitted from the solar collector. The exergy analysis of the collector can be obtained with Pridasawas et al. 2004 [28]:

Exergy (radiation) input: $\varphi=f \sigma T_{\text {sun }}^{4}+(1-f) \sigma T_{p}^{4}-\sigma T_{s c}^{4}$

where subscripts sun, $p$ and $s c$ stand for sun, planet and solar collector respectively, $f$ is the sunlight dilution factor equal to $2.16 \times 10^{-5}$ on earth. The solar radiation that reaches the solar collector is transformed into heat. This heat is partly absorbed by thermal fluid and the surrounding equipment and partly lost to the environment. The available solar radiation is transformed into available heat for the process; however, the second law of thermodynamics hinders the transformation of all heat into exergy. The exergy of the solar heat input to the solar collector is given by the relationship:

$$
\text { Exergy (heat) input: } \varphi_{s, h}=Q_{a v a}\left(1-\frac{T_{r e f}}{T_{s c}}\right)
$$

Exergy loss during the transformation process for each component is as follows: 


$$
I_{s c, r}=\varphi_{s}-\varphi_{s, h}
$$

The useful exergy gained by the solar collector is:

$$
\varphi_{s u}=Q_{u}\left(1-\frac{T_{r e f}}{T_{s c}}\right)
$$

where $Q_{u}$ is the useful steady state energy gain to the solar collector. The exergy loss from the input of solar collector to the working fluid can be calculated using the equation:

$$
\Delta \varphi_{s c}=\varphi_{s}-\varphi_{s u}-\Delta \varphi_{e n}-\Delta \varphi_{s c, r}
$$

where $\Delta \varphi_{s c, r}$ is the exergy lost during the transformation from solar energy radiation to heat on the solar collector and written as:

$$
\Delta \varphi_{s c, r}=\varphi_{s}-\varphi_{s, h}
$$

$\Delta \varphi_{e n}$ is the average loss caused by the wind effect on the solar collector. It's impossible to calculate a priori, since the speed, the direction and the sense of the wind are unknown [29]. Moreover, as the plate temperature is a function of $\Delta \varphi_{e n}, \Delta \varphi_{e n}$ cannot be determined either. For these reasons, it will be assumed for simplicity $\Delta \varphi_{e n}=0$ and therefore:

$$
\Delta \varphi_{s c}=\varphi_{s}-\varphi_{s u}-\Delta \varphi_{s c, r}
$$

The exergy loss for the solar assisted absorption refrigeration system is given by:

$$
\Delta \varphi_{\text {system }}=\Delta \varphi_{T}+\Delta \varphi_{S C}
$$

The following are the performance equations for each of the components considering the second law of thermodynamics (exergy balance).

\section{Generator}

Exergy available: $\varphi_{g e n}=Q_{g}\left(1-\frac{T_{r e f}}{T_{g}}\right)$

Exergy loss: $I_{g e n}=T_{r e f}\left(m_{g}\left(s_{3}-s_{1}\right)+m_{s c}\left(s_{g-s c-o u t}-s_{g-s c-i n}\right)\right)$

\section{Ejector}

Exergy loss: $I_{j}=T_{r e f}\left[\left(m_{e}+m_{g}\right) S_{6}-m_{g} S_{3}-m_{e} S_{9}\right]$

\section{Condenser}

Exergy loss: $I_{c}=T_{\text {ref }}\left(\left(m_{g}+m_{c}\right)\left(S_{7}-S_{6}\right)+\frac{Q_{c}}{T_{\text {ref }}}\right)$

Pump

Exergy loss: $I_{p}=W_{\text {pump }}+m_{g}\left[\left(h_{1}-h_{7}\right)-T_{\text {ref }}\left(S_{1}-S_{7}\right)\right]$

Expansion device

Exergy loss: $I_{\exp }=m_{e}\left[T_{r e f}\left(S_{8}-S_{7}\right)\right]$

\section{Evaporator}


Exergy delivered: $\varphi_{e}=Q_{e}\left(1-\frac{T_{\text {ref }}}{T_{\text {room }}}\right)$

Exergy loss: $I_{e}=T_{r e f}\left[m_{e}\left(S_{9}-S_{8}\right)-\frac{Q_{e}}{T_{\text {room }}}\right]$

The exergy efficiency for cooling is the ratio of the chilled water exergy at the evaporator to the exergy of the heat source at the generator:

$$
\varphi_{\text {cooling }}=\frac{m_{17}\left(\varphi_{17}-\varphi_{18}\right)}{m_{11}\left(\varphi_{11}-\varphi_{12}\right)}
$$

The exergetic efficiency for heating is the ratio of the combined supply of hot water exergy at the absorber and condenser to exergy of heat source at the generator:

$$
\varphi_{\text {heating }}=\frac{m_{15}\left(\varphi_{16}-\varphi_{15}\right)+m_{13}\left(\varphi_{14}-\varphi_{13}\right)}{m_{11}\left(\varphi_{11}-\varphi_{12}\right)}
$$

The second law efficiency of the absorption system is measured by the exergetic efficiency. A. Sözen et al. 2007 defined the exergetic coefficient of performance of an ARS:

$$
\operatorname{ECOP}_{\text {cooling }}=\frac{\dot{q}_{e}\left(1-\frac{T_{0}}{T_{e}}\right)}{\dot{q}_{g}\left(1-\frac{T_{0}}{T_{g}}\right)+\dot{W}_{p e}}=\frac{m_{10}\left(\varphi_{10}-\varphi_{9}\right)}{m_{7} \varphi_{7}+m_{3} \varphi_{3}-m_{4} \varphi_{4}}
$$

The coefficient of performance of the system for cooling purpose is:

$$
\text { COP } P_{\text {cooling }}=\frac{\dot{q}_{e}}{\dot{q}_{g}}=\frac{m_{10}\left(h_{10}-h_{9}\right)}{m_{7} h_{7}+m_{3} h_{3}-m_{4} h_{4}}
$$

For the mass balance, the different equations are given by O. Kaynakli et al. [30]:

$$
\begin{array}{cc}
\dot{m}_{w}=\dot{m}_{s}+\dot{m}_{\mathrm{H}_{2} \mathrm{O}} & \text { (Total mass balance) } \\
\dot{m}_{w} X_{w}=\dot{m}_{s} X_{s} & \text { (LiBr mass balance) }
\end{array}
$$

where $x$ is the $\mathrm{LiBr}$ concentration and subscripts $w$ and $s$ are for weak solution and strong solution respectively.

The flow rate of the strong and weak solutions can be determined from equations below:

$$
\begin{gathered}
\dot{m}_{s}=\frac{X_{w}}{X_{s}-X_{w}} \dot{m}_{\mathrm{H}_{2} \mathrm{O}} \\
\dot{m}_{w}=\frac{X_{s}}{X_{s}-X_{w}} \dot{m}_{\mathrm{H}_{2} \mathrm{O}}
\end{gathered}
$$

Properties of the $\mathrm{LiBr}-\mathrm{H}_{2} \mathrm{O}$ solution and typical overall heat transfer coefficient were adopted from Gur Mittelman [31]. For the heat transfer area or total conductance, we adopted the values: $(\mathrm{UA})_{\mathrm{a}}=1.800 \mathrm{~kW} / \mathrm{K},(\mathrm{UA})_{\mathrm{e}}=2.250 \mathrm{~kW} / \mathrm{K}$, 
$(\mathrm{UA})_{\mathrm{g}}=1.000 \mathrm{~kW} / \mathrm{K},(\mathrm{UA})_{\mathrm{c}}=1.200 \mathrm{~kW} / \mathrm{K}$.

\section{Results and Discussion}

During the first 30 min the system chiller needs to start up and at 6:30 AM when the sun rises the water temperature inside the collector start to increase; that's why an abnormal behaviour of some curves is observed before 7:00 AM. During this period, the solution temperature varies rapidly from the ambient temperature to the boiling temperature. The heat supplied to the generator during this period is small and partially used for running the machine until the different components reach the process temperature. Similar observation is made after 5:30 PM. This is because the auxiliary heater needs to start below a temperature not reached at those moments.

Table 2 shows the thermodynamic state of each of the points within the cycle, enthalpy, entropy and exergy can be slightly compared to that obtained by Talbi et al. [9] for the different points of the system. The values of the two studies are similar. The Table 3 shows the effectiveness of the generator, the absorber, the evaporator and the condenser. It is noted that the generator is a component with a low effectiveness. This indicates that the generator needs a particular attention and must be optimized.

Figure 2 shows the variation of insolation during the day chosen for our study. This curve has the same behaviour with that of the temperature of the

Table 2. Operating conditions for the cycle with heat exchangers at 12:30 pm.

\begin{tabular}{|c|c|c|c|c|c|c|}
\hline$i$ & $T(i)^{\circ} \mathrm{C}$ & $h(i)(\mathrm{kJ} / \mathrm{kg})$ & $s(i)(\mathrm{KJ} / \mathrm{kg})$ & $m(i)(\mathrm{Kg} / \mathrm{s})$ & $x(i)(\%) \mathrm{LiBr}$ & $\varphi(i)(\mathrm{kJ} / \mathrm{kg})$ \\
\hline 1 & 35 & 282.24 & 2.24 & 0.1836 & 60 & 151.18 \\
\hline 2 & 218 & 282.24 & 2.24 & 0.1836 & 60 & 151.18 \\
\hline 3 & 223 & 322.24 & 2.24 & 0.1836 & 60 & 191.16 \\
\hline 4 & 219.17 & 1200.33 & 2.24 & 0.1707 & 55 & 1135.72 \\
\hline 5 & 86 & 1237.00 & 2.24 & 0.1707 & 55 & 1172.39 \\
\hline 6 & 73 & 1237.00 & 2.24 & 0.1707 & 55 & 1172.39 \\
\hline 7 & 219.17 & 3429.00 & 6.11 & 0.0129 & - & 1138.61 \\
\hline 8 & 36.47 & 2620.18 & 8.33 & 0.0129 & - & -341.00 \\
\hline 9 & 38.47 & 2620 & 8.33 & 0.0129 & - & -341.00 \\
\hline 10 & 34.39 & 267319 & 8.37 & 0.0129 & - & -328.74 \\
\hline 11 & 129 & 2716.6 & 6.99 & 0.55 & - & 166.2 \\
\hline 12 & 71 & 2494.6 & 9.23 & 0.55 & - & -741.14 \\
\hline 13 & 35 & 146.76 & 0.50 & 0.25 & - & -7.27 \\
\hline 14 & 36 & 146.76 & 0.50 & 0.25 & - & -7.27 \\
\hline 15 & 35 & 146.76 & 0.50 & 0.4 & - & -7.27 \\
\hline 16 & 36 & 150.53 & 0.52 & 0.4 & - & -7.24 \\
\hline 17 & 35 & 146.76 & 0.50 & 0.28 & - & -7.27 \\
\hline 18 & 36 & 282.24 & 0.51 & 0.28 & - & -7.25 \\
\hline
\end{tabular}


Table 3. The effectiveness for each component.

\begin{tabular}{cc}
\hline Component & Effectiveness \\
\hline Generator & 0.35 \\
Condenser & 0.68 \\
Evaporator & 0.74 \\
Absorber & 0.78 \\
\hline
\end{tabular}

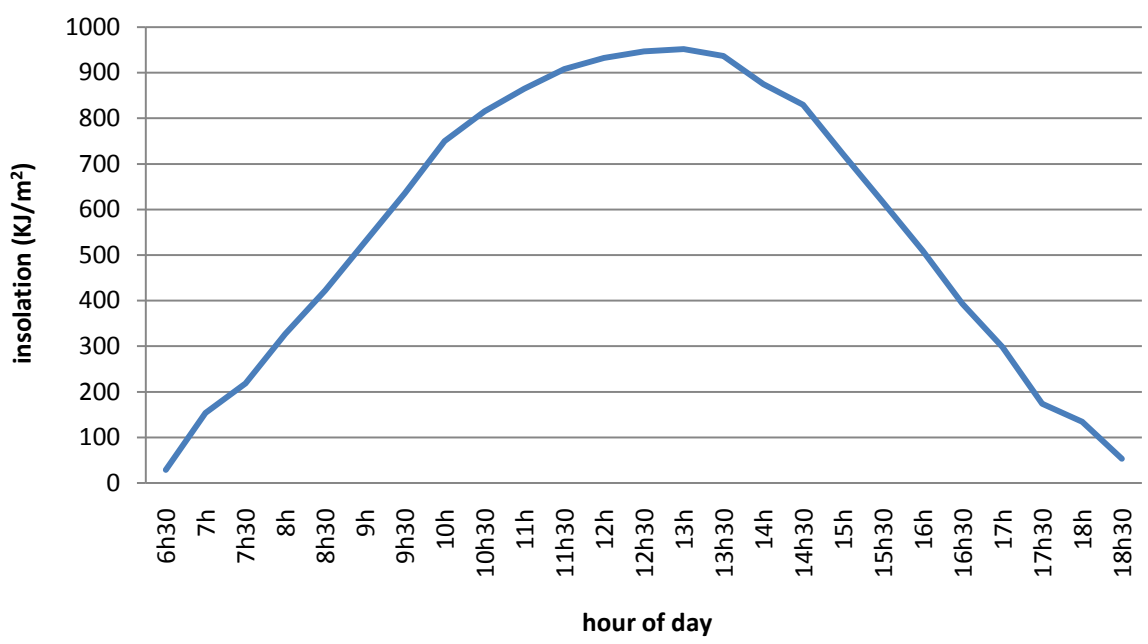

Figure 2. Variation of solar insolation during the day.

generator shown in Figure 3. The similar variation is observed in Figure 4, Figure 5 with the generator load, the solar collector temperature and the exergy gained by the fluid in the solar collector respectively. These curves reached their maximum at 12:30 PM when the ambient temperature is also maximum. Figure 6 shows the variation of the $C O P$ and $E C O P$ of cooling during the day. The $C O P$ and $E C O P$ depend on the generator load $Q_{g e}$ and the evaporator load $Q_{e r}$ The evaporator load remains constant while the generator load increases. That's while instead of having $C O P$ and $E C O P$ which with the temperature of the generator, we can observe a decreasing. Figure 7 shows the variation of $C O P$ and $E C O P$ of cooling with the temperature of the generator. Figure 8 represents the variation of the exergy of the solar collector during the day which follows the variation of ambient temperature. Figure 9 presents the variation of the exergy gained by the fluid in the solar collector during the day. One can observe that the exergy gained also by this important component of the system has the same evolution with the insolation. Figure 10 shows the exergy loss of condenser. The energy remove from the refrigerant at this level makes the exergy loss decreasing. The variation of the exergy loss of absorber along the day is shown in Figure 11. This component is very complex with the fact that it's where the weak solution and the refrigerant are mixed to form the strong solution. The exergy loss is negative because the disorder (entropy) is higher than the order (enthalpy). Figure 12 shows the exergy loss of generator that presents a diminution around 


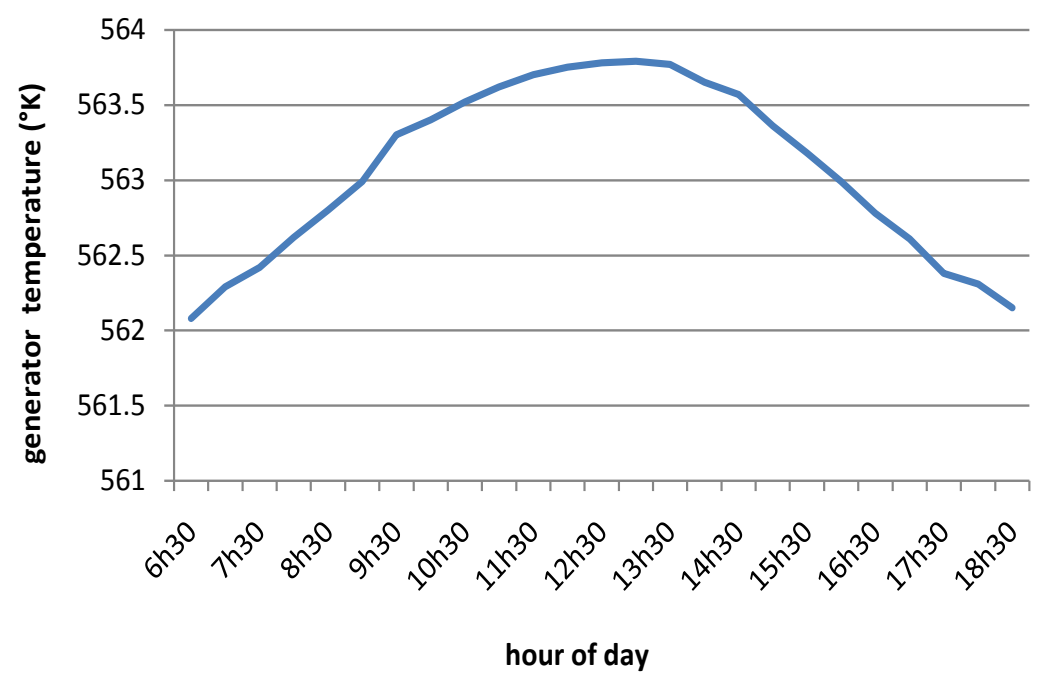

Figure 3. Variation of the generator temperature during the day.

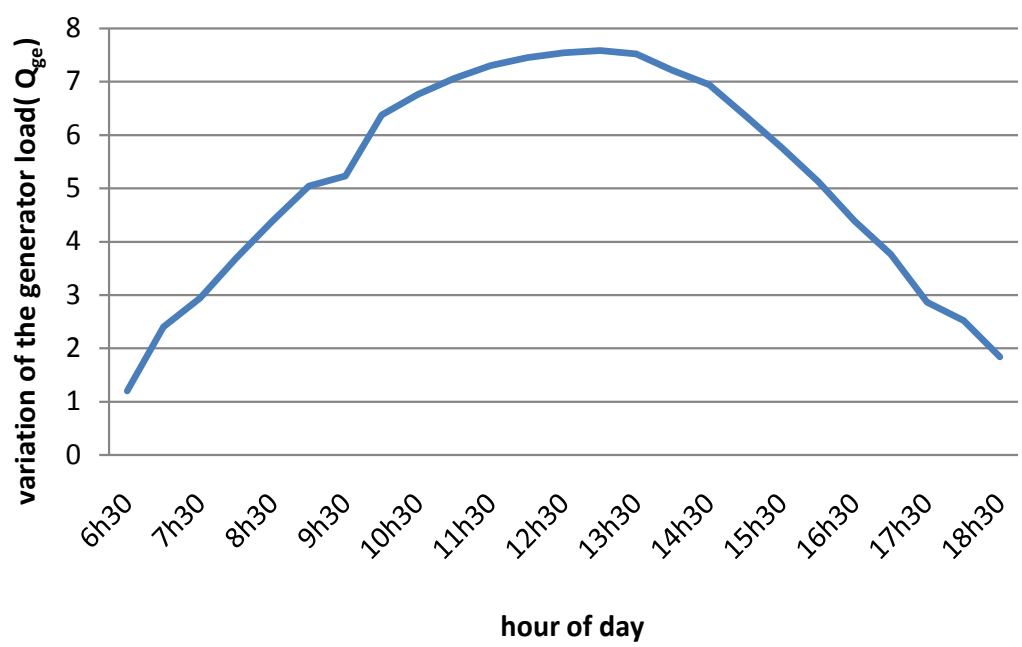

Figure 4. Variation of the generator load $Q_{g e}$ during the day.

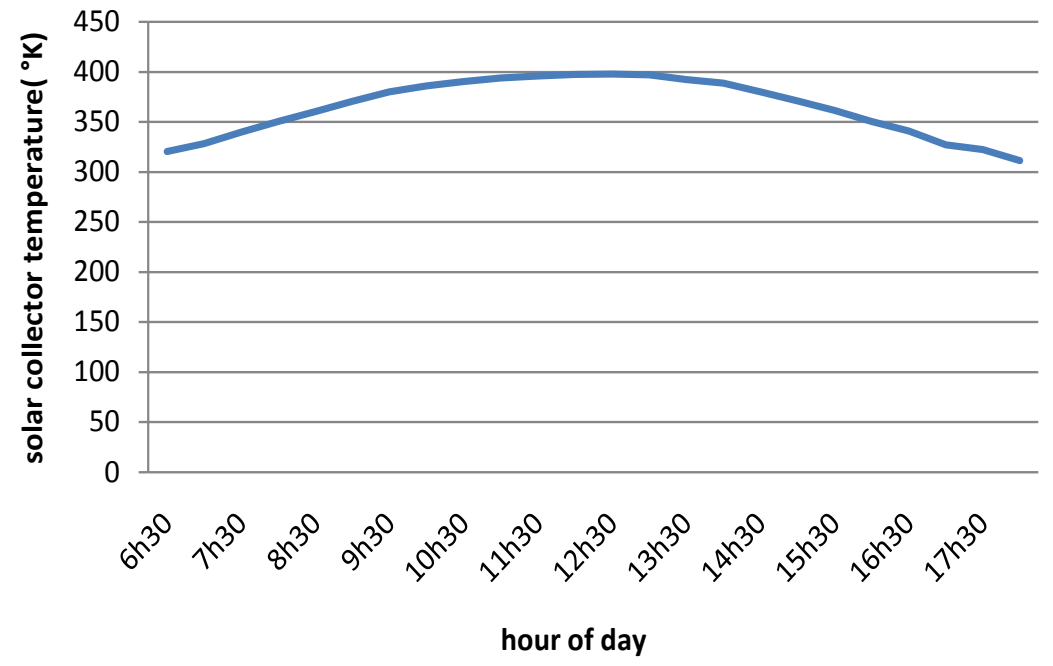

Figure 5. Variation of the temperature of the solar collector. 


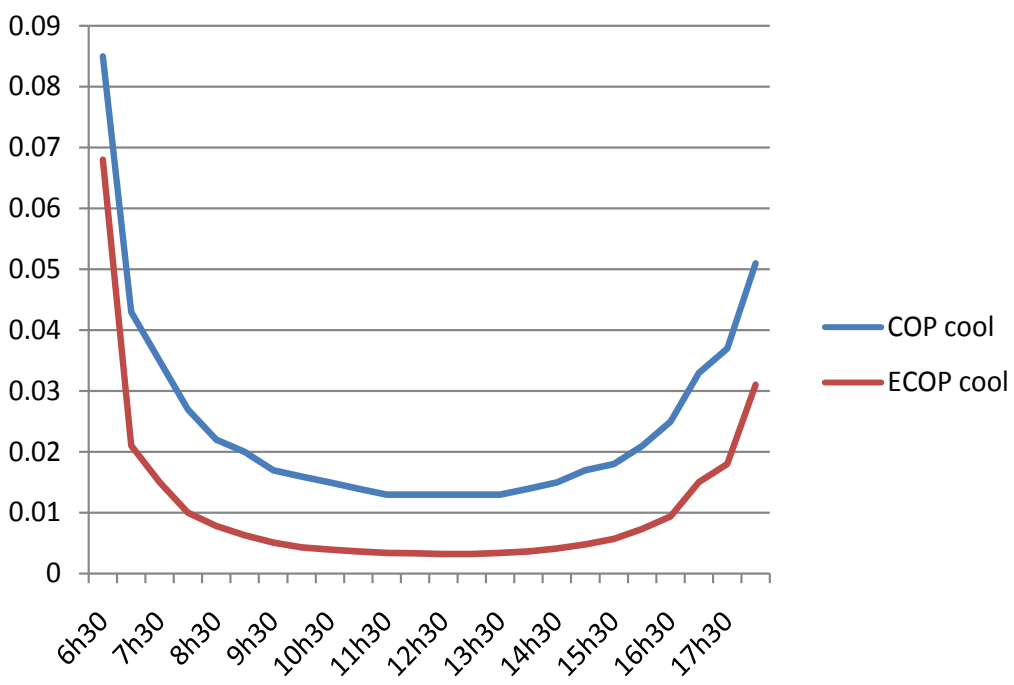

Figure 6. Variation of the $C O P$ and $E C O P$ of cooling during the day.

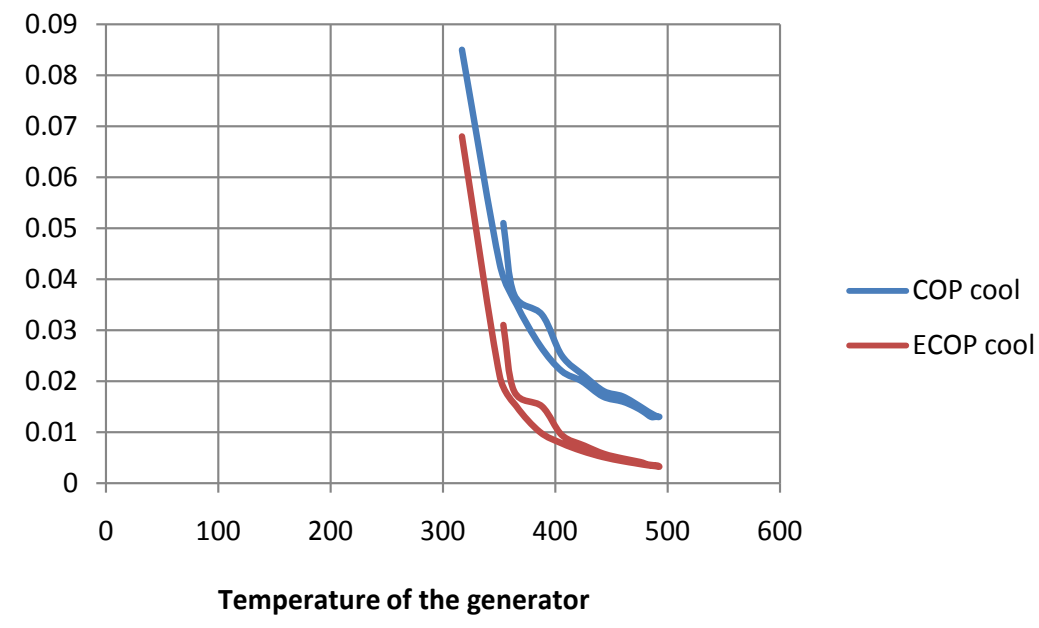

Figure 7. Variation of $C O P$ and $E C O P$ with temperature of generator.

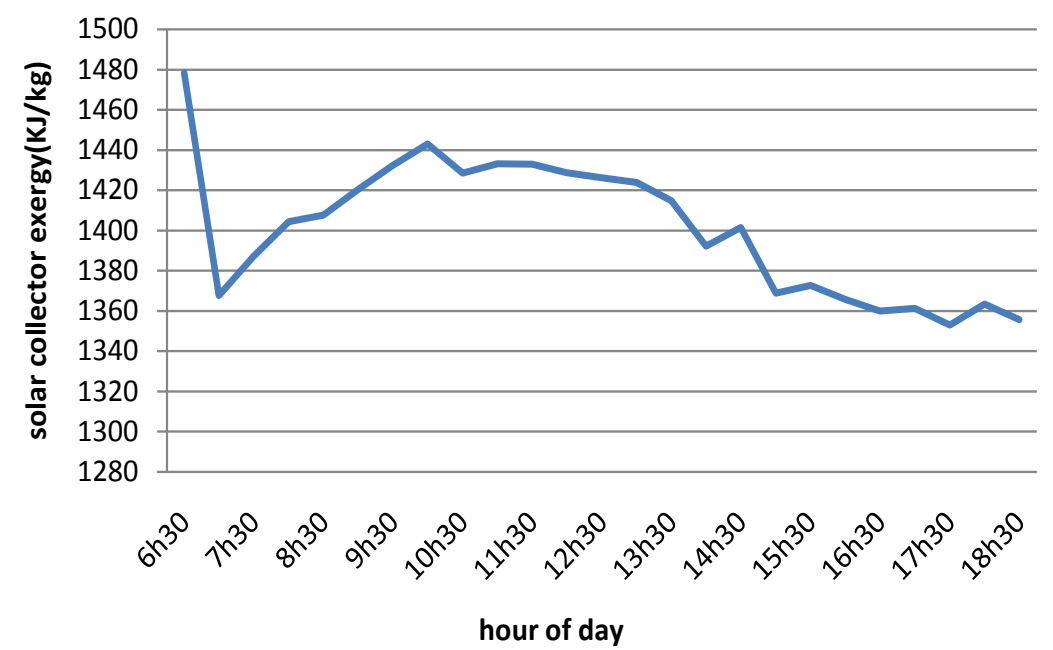

Figure 8. Variation of the exergy gain by the solar collector. 


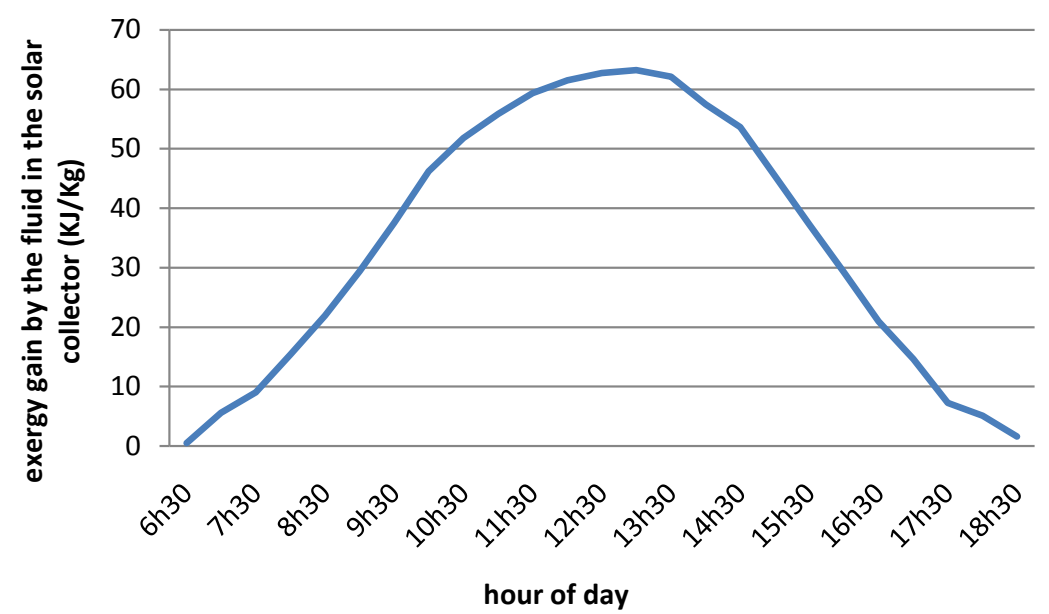

Figure 9. Variation of the exergy gain by the fluid in the solar collector.

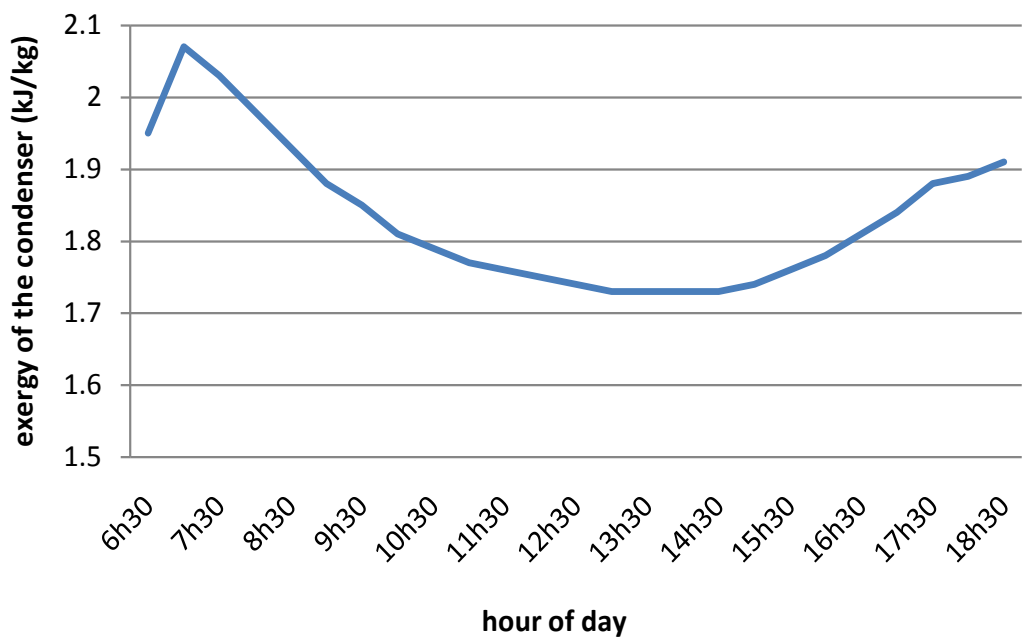

Figure 10. Variation of the exergy loss of the condenser.

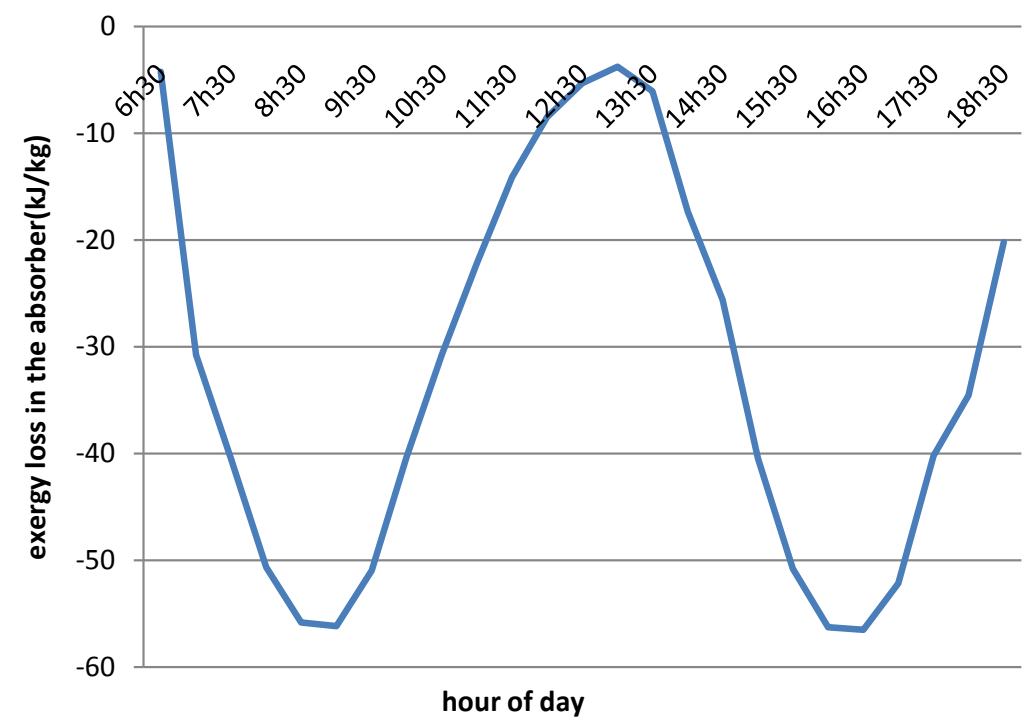

Figure 11. Variation of the exergy loss of absorber during the day. 


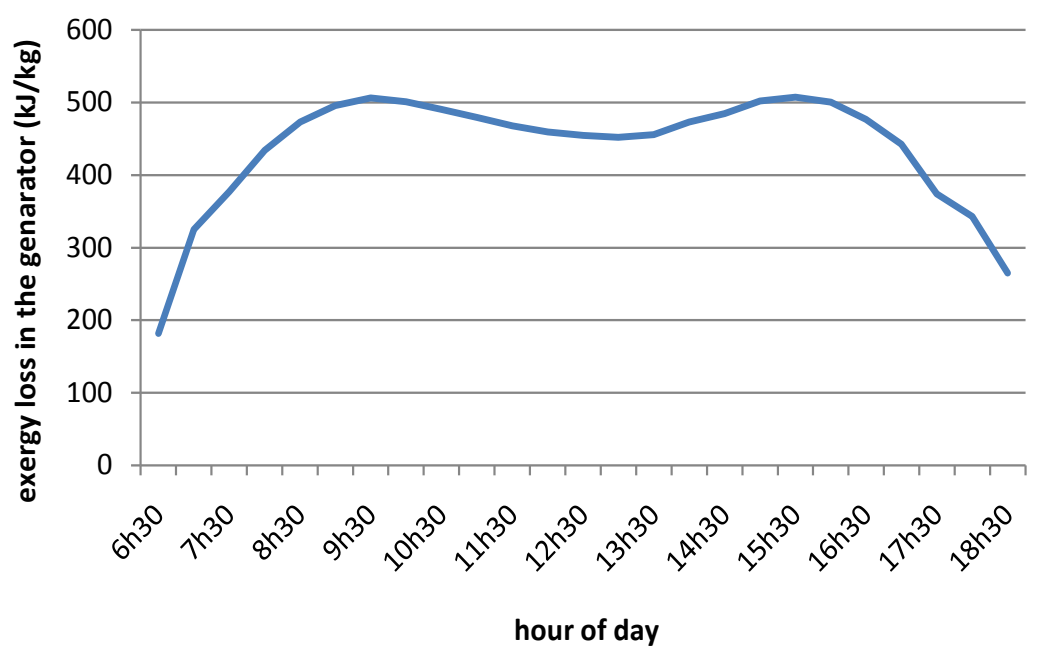

Figure 12. Variation of the exergy loss in the generator during the day.

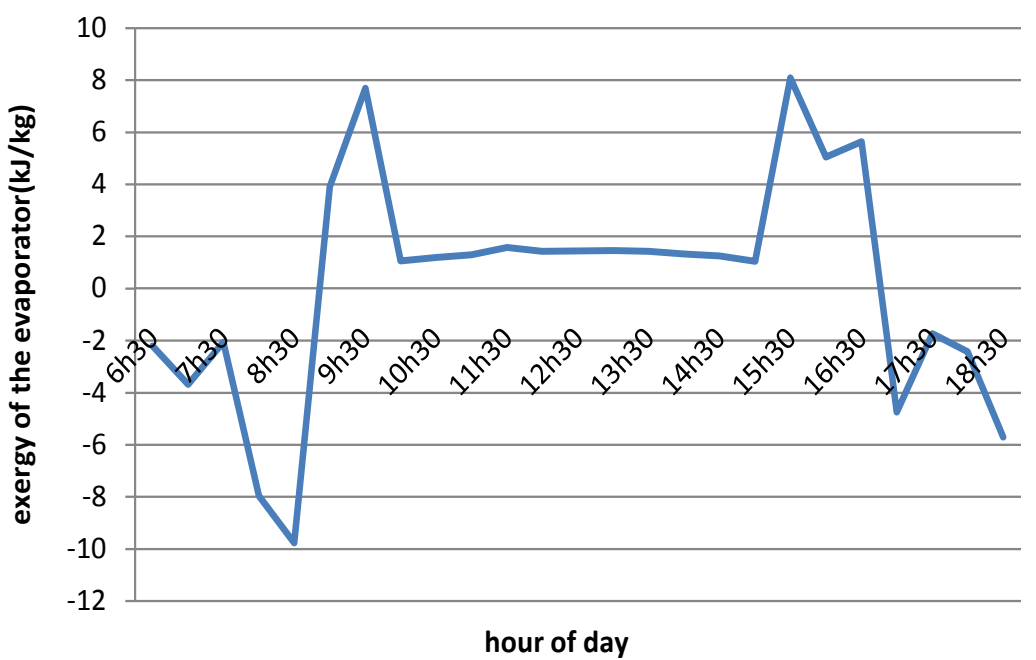

Figure 13. Variation of the exergy loss of evaporator.

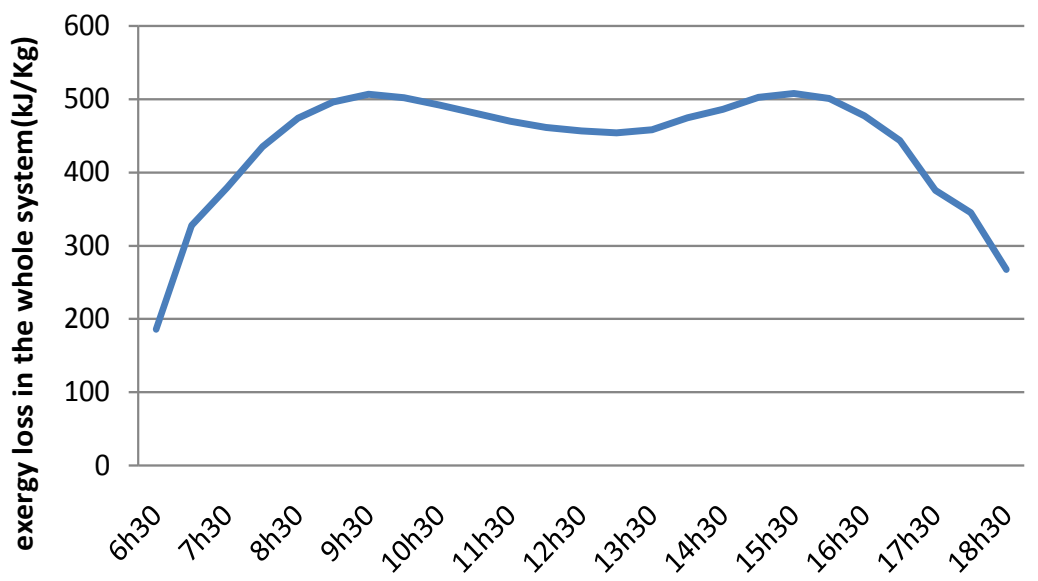

hour of day

Figure 14. Evolution of the exergy loss of the whole system. 
12:30 PM. This behaviour is normal because the insolation is high and the energy needed to run the system during this period is available. Figure 13 presents the exergy loss of evaporator which is constant during the permanent period that is from $10 \mathrm{AM}$ to $4 \mathrm{PM}$. Transitory periods which are before $10 \mathrm{AM}$ and after 4 PM show the necessity of an auxiliary heater. Figure 14 illustrates the variation of exergy loss of the whole system during the day. It's the same evolution with the exergy loss of the generator. This demonstrates the importance of the generator for absorption refrigeration systems.

\section{Conclusions}

By applying the first and the second laws of thermodynamics, the exergy analysis of a single-effect solar absorption refrigeration which working pair is $\mathrm{LiBr}-\mathrm{H}_{2} \mathrm{O}$ has been performed under weather conditions of Ngaoundere city, Cameroon of the $15^{\text {th }}$ January 2014 . The study was made throughout the middle of the dry season. The exergy loss of the absorption cooling device and half hourly exergy destruction values of components were determined. The $C O P$ and the ECOP of the system were also investigated.

The main conclusions obtained from the present study are as follows:

1) The maximum exergy destruction occuring in the solar energy assistance system is in the generator and the solar collector of the absorption cooling device.

2) The exergy losses in the generator and in the absorber alternate; this is coherent because the generator absorbs energy while the absorber liberates energy.

3) The half hourly study has enabled us to have more accurate analysis of the exergy of the system. By doing this, we have investigated a more accurate study of the system.

The system can be implemented in Cameroon and in countries with high solar availability.

\section{References}

[1] Florides, G.A.,Tassou, S.A., Kalogirou, S.A. and Wrobel, L.C. (2002) Review of Solar and Low Energy Cooling Technologies for Buildings. Renewable and Sustainable Energy Reviews, 6, 557-572. https://doi.org/10.1016/S1364-0321(02)00016-3

[2] Sözen, A. (2001) Effect of Heat Exchangers on Performance of Absorption Refrigeration Systems. Energy Conversion and Management, 42, 1699-1716. https://doi.org/10.1016/S0196-8904(00)00151-5

[3] Lior, N. and Zhang, N. (2007) Energy, Exergy, and Second Law Performance Criteria. Energy, 32, 281-296. https://doi.org/10.1016/j.energy.2006.01.019

[4] Ravikumar, T.S., Suganthi, L. and Anand A.S. (1998) Exergy Analysis of Solar Assisted Double Effect Absorption Refrigeration System. Renewable Energy, 14, 55-59. https://doi.org/10.1016/S0960-1481(98)00047-0

[5] Hasan, A.A., Goswami, D.Y. and Vijayaraghavan S. (2002) First and Secondlaw Analysis of a New Power and Refrigeration Thermodynamic Cycle Using a Solar Heat Source. Solar Energy, 73, 385-393. https://doi.org/10.1016/S0038-092X(02)00113-5

[6] Ghaddar, N.K., Shihab, M. and Bdeir, F. (1997) Modeling and Simulation of Solar 
Absorption System Performance in Beirut. Renewable Energy, 10, 539-558. https://doi.org/10.1016/S0960-1481(96)00039-0

[7] Ezzine, N.B., Barhoumi, M., Mejbri, K., Chemkhi, S. and Bellagi, A. (2004) Solar Cooling with the Absorption Principle: First and Second Law Analysis of an Ammonia-Water Double-Generator Absorption Chiller. Desalination, 168, 137-144. https://doi.org/10.1016/j.desal.2004.06.179

[8] Fellah A., Hamed, M. and Brahim, A.B. (2014) On the Performance of a Solar Driven Absorption Refrigerator. Energy and Power Engineering, 6, 278-291. https://doi.org/10.4236/epe.2014.69024

[9] Talbi, M.M. and Agnew, B. (2000) Exergy Analysis: An Absorption Refrigerator Using Lithium Bromide and Water as Working Pair. Applied Thermal Engineering, 20, 619-630. https://doi.org/10.1016/S1359-4311(99)00052-6

[10] Onan, C., Ozkan, D.B. and Erdem, S. (2010) Exergy Analysis of a Solar Assisted Absorption Cooling System on an Hourly Basis in Villa Applications. Energy, 35, 5277-5285. https://doi.org/10.1016/j.energy.2010.07.037

[11] Li, H.Y., Huang, T.F., Tsai, M.C., Lee, Y.W., Yuan, S.L., Tsai, M.J. and Ai, C.F. (2013) Energy and Exergy Analysis of a New Small Concentrating Solar Power Plant. Energy and Power Engineering, 5, 300-305. https://doi.org/10.4236/epe.2013.54B059

[12] Wei, J., Yang, L. and Yu, G. (2013) Experimental Study of Solar-Assisted Heating System. Energy and Power Engineering, 5, 151-156.

[13] Tubreoumya, G.C., Dissa, A.O., Tiendrebeogo, E.S., Chesneau, X., Compaoré, A., Haro, K., Konseibo, C.D., Zeghmati, B. and Koulidiati, J. (2017) Contribution to the Modeling of a Solar Adsorption Refrigerator under the Climatic Conditions of Burkina Faso. Energy and Power Engineering, 9, 119-135. https://doi.org/10.4236/epe.2017.92010

[14] Atmaca, I. and Yigit, A. (2003) Simulation of Solar-Powered Absorption Cooling System. Renewable Energy, 28, 1277-1293.

[15] Florides, G.A., Kalogirou, S.A., Tassou, S.A. and Wrobel, L.C. (2003) Design and Construction of a LiBr-Water Absorption Machine. Energy Conversion and Management, 44, 2483-2508.

[16] Florides, G.A., Kalogirou, S.A., Tassou, S.A. and Wrobel, L.C. (2002) Modelling, Simulation and Warming Impact Assessment of a Domestic-Size Absorption Solar Cooling System. Applied Thermal Engineering, 22, 1313-1325.

[17] Papadopoulos, A.M., Oxizidis, S. and Kyriakis, N. (2003) Perspectives of Solar Cooling in View of the Developments in the Air-Conditioning Sector. Renewable and Sustainable Energy Reviews, 7, 419-438.

[18] Assilzadeh, F., Kalogirou, S.A., Ali, Y. and Sopian, K. (2005) Simulation and Optimization of a LiBr Solar Absorption Cooling System with Evacuated Tube Collectors. Renewable Energy, 30, 1143-1159.

[19] Pongsid, S., Satha, A. And Supachart, C. (2001) A Review of Absorption Refrigeration Technologies. Renewable and Sustainable Energy Review, 5, 343-372.

[20] Fan, Y., Luo, L. and Souyri, B. (2007) Review of Solar Sorption Refrigeration Technologies: Development and Applications. Renewable and Sustainable Energy Reviews, 11, 1758-1775.

[21] Sun., D. (1997) Thermodynamic Design Data and Optimum Design Maps for Absorption Refrigeration Systems. Applied Thermal Engineering, 17, 211-221.

[22] Sözen, A. and Özalp, M. (2003) Performance Improvement of Absorption Refrigera- 
tion System using Triple-Pressure-Level. Applied Thermal Engineering, 23, 1577-1593.

[23] Ardehali, M.M., Shahrestani, M. and Adams, C.C. (2007) Energy Simulation of Solar Assisted Absorption System and Examination of Clearness Index Effects on Auxiliary Heating. Energy Conversion and Management, 48, 864-870.

[24] Kouremenos, D.A., Rogdakis, E.D. and Houzouris, G.E. (1994) A Thermodynamic Study of Non-Equilibrium Processes in the $\mathrm{H} 2 \mathrm{O} / \mathrm{LiBr}$ Absorption Refrigeration Machine Units. In: Thermodynamics and Design, Analysis, and Improvement of Energy Systems, ASME, New York, Vol. 33, 291-298.

[25] Şencan, A., Kemal, A., Yakut, S. and Kalogirou, A. (2005) Exergy Analysis of Lithium Bromide/Water Absorption Systems. Renewable Energy, 30, 645-657.

[26] Sözen, A. and Serdar Yücesu, H.S. (2007) Performance Improvement of Absorption Refrigeration System using Triple-Pressure-Level. Renewable Energy, 32, 267-284.

[27] De Vos, A. (1993) The Endoreversible Theory of Solar Energy Conversion: A Tutorial. Solar Energy Materials and Solar Cells, 31, 75-93.

[28] Pridasawas, W. and Lundqvist, P. (2004) An Exergy Analysis of a Solar-Driven Ejector Refrigeration System. Solar Energy, 76, 369-379.

[29] Millán, M.I., Hernández, F. and Martín, E. (1997) Available Solar Exergy in an Absorption Cooling Process. Solar Energy, 60, 367-377.

[30] Kaynakli, O. and Kilic, M. (2007) Theoretical Study on the Effect of Operating Conditions on Performance of Absorption Refrigeration System. Energy Conversion and Management, 48, 599-607.

[31] Mittelman, G., Kribus, A. and Dayan, A. (2007) Solar Cooling with Concentrating Photovoltaic/Thermal (CPVT) Systems. Energy Conversion and Management, 48, 2481-2490. 


\section{Nomenclature}

$C O P$ : coefficient of performance

ECOP: exergetic coefficient of performance

$h$ : enthalpy

$s$. entropy

$m$ : mass flow rate

$Q$ : heat flow rate

T: temperature

$P$ : pressure

$\varphi$ : exergy

$x$. mass fraction of lithium bromide

Dpsi: variation of exergy of the system

\section{Subscript}

ref. reference

g. ge: generator

e: evaporator

a: absorber

c. condenser

$j$ : ejector

exp: expansion valve

pump: pe: pump

sc. solar collector

ava: available 